\title{
A crítica ao sacerdócio e aos governantes segundo Os 5,1-7
}

\section{Criticism on the Priesthood and Rulers according to Os 5:1-7}

Maria de Lourdes Corrêa Lima

\section{Resumo}

O texto de Os 5,1-7 oferece não poucas dificuldades ao intérprete. Essas vão desde problemas de crítica textual e terminologia utilizada até a menção de locais ligados a tradições, e incluem ainda a menção de três destinatários aparentemente desconexos entre si. O presente estudo visa esclarecer esses elementos e chegar a indicar a finalidade do texto em seu conjunto.

Palavras-chave: Profecia de Oseias. Sacerdócio e monarquia em Israel. Mizpah. Tabor. Sitim.

\begin{abstract}
The text of Hos 5: 1-7 offers a number of difficulties for an interpreter. These range from problems of textual criticism and terminology, naming of locations linked to specific traditions, and the mention of three apparently disconnected recipients of the text. The present study aims to clarify these elements and to achieve an indication of the purpose of the text as a whole.
\end{abstract}

Keywords: Hosea's prophecy. Priesthood and monarchy in Israel. Mizpah. Tabor. Sitim. 


\section{Introdução}

Com exceção dos comentários ao livro de Oseias, pouca atenção se tem dado ao texto de Os 5,1-7. A tradição massorética apresenta graves problemas textuais, considerados por alguns como insolúveis e, de outro lado, as versões antigas apresentam lições variadas. A isso acrescentemse verdadeiros problemas de interpretação. Já o primeiro versículo se abre com o endereçamento a três destinatários, difíceis de precisar. A seguir, são elencados locais do Reino do Norte, porém sem que estejam claras as tradições aí evocadas. Acrescente-se a isso a pergunta acerca do tipo de delito que é reprovado e qual o sentido de alguns termos e expressões.

Em vista de indicar caminhos para uma resposta a estas e outras questões colocadas pelo texto, procurar-se-á considerá-lo dentro do contexto do livro, particularmente dos capítulos anteriores. Tal perspectiva se fundamenta no fato de que o escrito de Oseias apresenta significativa unidade interna de pensamento e terminologia, de um lado, e de que o capítulo 5 supõe os capítulos anteriores para sua compreensão, de outro. Para tanto, após a consideração da organização do texto, partir-se-á da identificação dos destinatários mencionados (v.1a-d) para considerar, em seguida, o problema reprovado (vv. 3-7) e as tradições ligadas aos lugares referidos no texto (vv.1 ef. 2). Isto será precedido da análise da organização do texto, que permitirá identificar as vozes que falam e o modo como a argumentação é desenvolvida. A partir dos dados levantados nas etapas anteriores, visa-se delinear, enfim, o objetivo do texto.

\section{O movimento do texto}

Os três imperativos em 5,1 marcam o início de uma nova unidade textual no livro de Oseias, identificada também pela diferença de temática em relação a 4,4-14.15-19. Apesar da mudança do endereçamento direto no v. 1 para a referência aos destinatários em terceira pessoa (vv. 2-7, com uma única exceção no v. 3c), o discurso desenvolve-se coerentemente, sem rupturas, até o v. 7, cujas afirmações manifestam um tom conclusivo. $\mathrm{O}$ chamado a tocar o chofar em 5,8 e a mudança de temática a partir de então confirmam a finalização da perícope no v. $7 .{ }^{1}$

\footnotetext{
${ }^{1}$ Diferentemente do aqui exposto, o estudo clássico de K. Elliger, um dos poucos que abordaram o texto em questão, desenvolve vasta argumentação para demonstrar que os vv. 1-2 formam uma unidade à parte: ELLIGER, K., Eine verkannte Kunstform bei Hosea (Zur Einheit von Hos 51f.), p. 151-160.
} 
A partir da pessoa que fala, dos pronomes concernentes aos destinatários e da observação das formas verbais e sua sequência, pode ser percebida a organização dos versículos em três seções.

O v. 1 abre o texto com o chamado a ouvir, dirigida a "vós". O aparecimento da $1^{\mathrm{a}}$ pessoa de YHWH no v. 2 poderia fazer pensar que seja também Deus quem fala no v. 1. No entanto, no v. 2 mudam os destinatários, de "vós" para "eles", marcando uma diferenciação no modo de falar. Com isso, parece ser mais verossímil considerar os dois versículos como pronunciados por dois falantes diferentes: enquanto no segundo é claro o "Eu" de YHWH, no primeiro estaria a fala do profeta.

Se o v. 2, com a menção de Sitim, cria uma ponte com os dois locais mencionados no v. 1, a mudança da pessoa de referência para os destinatários e da pessoa que fala marca uma ruptura para o que vem anteriormente. Nos vv. 2-3, a fala YHWH manifesta a sentença a que o profeta anteriormente chamara a atenção. O povo, referido primeiramente em $3^{\mathrm{a}}$ pessoa (eles, Efraim, Israel), após o עַתָּה ("agora"), que aponta para uma entrada importante no discurso, é interpelado primeiramente em $2^{\mathrm{a}}$ pessoa mas volta a ser mencionado, logo a seguir, em $3^{\mathrm{a}}$ pessoa (Israel). O עַתָּה que fecha a fala de YHWH, tem sua correspondência no עַתָּה que finaliza o v. 7 e corrobora o corte da fala de YHWH neste ponto.

Nos vv. 4-7 retorna o comentário do profeta, sendo Deus referido, a partir de então, sempre em $3^{\mathrm{a}}$ pessoa. Também o povo é mencionado sempre em $3^{\mathrm{a}}$ pessoa, alternando-se, porém, o singular e o plural.

a) Primeira seção: a exortação do profeta (v. 1)

O v. 1 está organizado em duas partes, demarcadas seja pelo uso de Imperativos seja por frases iniciadas por כִִּ

O chamado inicial utiliza três verbos do campo semântico da audição, dirigidos, por sua vez, a três grupos. A sequência dos destinatários coloca os sacerdotes em primeiro lugar e a "casa do rei" em última posição, ambos em torno da "casa de Israel". Cada qual tem, assim, posição de destaque de acordo com o ângulo de vista considerado.

A seguir é dada uma dupla fundamentação para o chamado, que se distingue, porém, na sua valência semântica: enquanto a primeira, com uma proposição nominal simples, complementa o chamado de atenção indicando seu objeto ("pois para vós é a sentença"), a segunda, em qatal, indica seu 
motivo, com referência a dois locais. São utilizadas aí duas imagens do âmbito da caça, cada qual relativa a um dos locais mencionados.

Em esquema:

Triplo chamado:

escutai

- sacerdotes

prestai ouvidos ouvi

- casa de Israel

Dupla fundamentação:

para vós é a sentença

$\begin{array}{ll}\text { fostes um laço } & \text { - em Mizpah } \\ \text { uma rede estendida } & \text { - no Tabor }\end{array}$

Com essa estrutura, o v. 1 aparece em forma de exortação.

b) Segunda seção: o discurso de YHWH (vv. 2-3)

A palavra de YHWH organiza-se em três momentos.

O v. 2 inicia-se com a menção de um malfeito no presente que continua o realizado em Sitim; segue-se daí a sentença de punição. Esta dá ênfase ao Eu de YHWH pela explicitação do pronome אִנִ e chama, portanto, para si, a atenção como ponto alto deste versículo.

O עַתָ do v. 3 distingue aí dois momentos. O primeiro é formulado com um duplo paralelismo semântico - Efraim/Israel, conhecer/não estar oculto - com variação de sujeito: YHWH no início, enfatizado, como no v. 2, pela menção explícita do pronome de $1^{a}$ pessoa; e Israel em seguida. $\mathrm{O}$ segundo momento contém também duas frases com termos em paralelismo semântico: Efraim/Israel, na mesma sequência do v. 3ab, e prostituir-se/contaminar-se. A utilização do endereçamento direto a Efraim no v. $3 \mathrm{c}$, juntamente com o sinal macrossintático עִ עָ chamam a atenção para esta declaração como ponto alto do discurso, de modo que a última linha (v. 3d: "contaminou-se Israel") não explicita uma ideia mais alta, mas sim complementa o que foi dito.

Pelo significado e o vocabulário empregado, o discurso de YHWH apresenta-se como uma acusação com indicação de punição (v. 2b).

Em esquema:

v. 2: referência local (Sitim)

v. 3: dois grupos de frases:

YHWH como pessoa de referência: paralelismo ידע ("conhecer") / לא כחד ("não estar oculto")

Efraim / Israel como referência: paralelismo ("prostituir-se") /

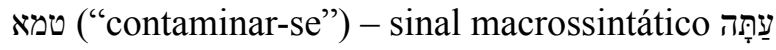


c) Terceira seção: o comentário do profeta (vv. 4-7)

O v. 4ab apresenta uma declaração seguida de dupla motivação, introduzida pela conjunção יכִ, que, embora ocorrendo somente no v. 4b ("sim, um espírito de prostituição está em seu meio"), rege tanto este segmento como o seguinte ("e não conhecem o Senhor"). Este, numa estrutura de qatal e com ênfase no nome de Deus, marca um primeiro ponto de repouso. A fundamentação retoma elementos do discurso de YHWH (v. 3), com a utilização das mesmas raízes זנהע e A ideia do "espírito de prostituição" (v. 4c) explicita "tu te prostituíste" (v. 3d), enquanto se sublinha a oposição entre os israelitas que "não conhecem o Senhor" (v. 4d) e o Senhor que "conheceu Efraim" (v. 3a). Com isso, o comentário do profeta demonstra-se fiel ao que o Senhor falou. A dupla menção do verbo ידע no início do v. 3 e no final do v. 4 criam uma moldura que une a palavra de YHWH à reflexão do profeta.

O v. 5 utiliza como sujeito, inicialmente, um abstrato (o "orgulho": (גָּז tem efeito contrário. Daí as consequências, que ocorrem com a metáfora do tropeçar (v. 5bc). Os sujeitos são Israel e Efraim, apresentados em ordem inversa àquela do v. 3 , mas cuja repetição, por outro lado, por retomarem o discurso divino, reafirma por mais um título a palavra do profeta como calcada na acusação de Deus. A metáfora termina com a utilização de um

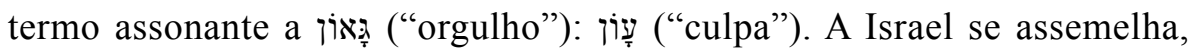
por fim, também o reino de Judá (v. 5c). O 0-qatal ${ }^{2}$ desta última frase marca o fim da primeira subseção. $\mathrm{O}$ v. 6 , de fato, explicitará a atitude de Israel como a busca do Senhor através de atos cultuais, o que até então não fora mencionado.

O v. 6 baseia-se no esquema buscar (בקש) - encontrar (מצא), mas aqui contrastado: buscarão o Senhor sem encontrá-lo. Também o "afastar-se" (מלץ) da última linha se contrapõe ao movimento de ida ao encontro mencionado na primeira linha ("caminharão"הלך). O motivo aparece na frase final, que, também construída em 0-qatal, conclui a menção do âmbito cultual. Prepara, dessa maneira, o clímax do discurso, que ocorre no v. 7.

Neste último, duas frases em estrutura de qatal resumem as ideias principais, retomando, com outra terminologia, o tema da prostituição ("filhos

${ }^{2} \mathrm{O} 0$ enfatiza que a forma verbal ocupa a primeira posição na frase. 


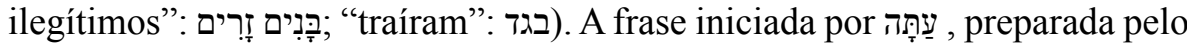

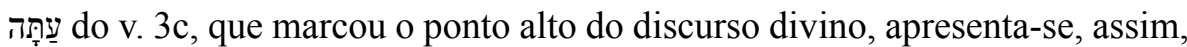
como ponto de chegada de todo o conjunto.

Os vv. 4-7 apresentam, assim, quatro momentos, delimitados pela repetição de frases em qatal nos v. $4 c, 5 c$ e $6 c$. Pela semântica e a utilização de formas verbais em sentido futuro, o comentário do profeta aparece como um discurso preditivo.

Em esquema:

v. 4: as obras não permitem a conversão - motivos: espírito de prostituição / falta de conhecimento de Deus

v. 5: o orgulho testemunha contra eles - resultado: tropeçará Israel / tropeçará Efraim / tropeçará Judá

v. 6: esquema caminhar (ir ao encontro) - buscar - não encontrar afastar-se

v. 7: síntese: trair / gerar filhos ilegítimos (7ab) clímax: עִ (7c)

d) O conjunto

A conjugação, num único texto, do discurso divino com o comentário do profeta, que desenvolve o sentido do pronunciamento de YHWH, é marcada pelos imperativos iniciais, com a exortação a ouvir. Esta, abrindo todo o conjunto, serve de elemento integrador de suas partes. Com efeito, introduz tanto o discurso de Deus como as observações posteriores do profeta, de forma que é a totalidade dos vv. 2-7 o objeto da audição requerida.

Por outro lado, como, na exortação inicial, já é indicada a culpabilidade de Israel e sua consequência, a sentença divina (טִ̣ , v. 1d), o texto como um todo surge como um discurso de acusação e condenação.

\section{Comentário}

Serão consideradas as seções do texto, com exceção das menções aos locais, que, por pertencerem seja à exortação inicial seja ao discurso divino, serão tratadas à parte. 


\subsection{Os destinatários (vv. 1a-d)}

Escutai isto, sacerdotes;

prestai atenção, casa de Israel;

casa do rei, prestai ouvidos,

pois para vós é a sentença.

Embora os três verbos utilizados na abertura do texto - ouvir, prestar atenção, prestar ouvidos - apresentem distinções entre si, pertencem todos ao mesmo campo semântico, o que permite colocar os três grupos como destinatários igualmente das palavras que se seguem.

- O primeiro grupo não oferece dificuldades de identificação. Os "sacerdotes" são bem conhecidos do livro e aparecem sempre com conotação negativa. Trata-se certamente de sacerdotes javistas, que atuam em Betel e Guilgal ${ }^{3}(4,15)$, desviados e responsáveis pelos desvios do povo $(4,4.6 .9)$, comparados a salteadores no caminho $(6,9)$.

- O terceiro grupo, "casa do rei" indica certamente a corte, os funcionários, dentre os quais os príncipes ( שָׁרִים: 7,3.5) e talvez também o próprio monarca.

- A "casa de Israel" é interpretada como sendo o povo em seu conjunto $^{5}$ ou como se referindo aos chefes de clãs israelitas. ${ }^{6} \mathrm{~A}$ análise das ocorrências desta última expressão no livro, todavia, aponta em outra direção. Em 1,4-5, "fazer cessar o reinado da casa de Israel” está ligado a "quebrar o arco de Israel"; em 1,6-7, "casa de Israel" está contraposta a "Judá”; em 12,1, é mencionada junto com Efraim e Judá. Esse panorama faz pensar que a expressão designe o Reino do Norte enquanto entidade política, que poderia ser representado também, mas não exclusivamente, pelos chefes de clã.

\footnotetext{
3 Am 5,5. As tradições bíblicas antigas não consideraram os santuários de Betel e Guilgal como idolátricos. Elias e Eliseu, por exemplo, não se opõem a eles, mas sim aos profetas sacerdotes de baal (1Rs 13,11; 2Rs 2,2). E a purificação religiosa de Jeú parece não ter eliminados o bezerro de ouro que se encontravam em Betel e Dã (2Rs 10,28-29). A imagem do bezerro parece ter sido sinal da presença do Senhor e não uma sua representação. RINGGREN, H.,

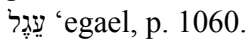

${ }^{4}$ WOLFF, H. W., Hosea, p. 123.

${ }^{5}$ MCCOMISKEY, T. E., Hosea, p. 75.

${ }^{6}$ WOLFF, H. W., Hosea, p. 123; JEREMIAS, J., Der Prophtet Hosea, p. 74; CRAIGIE, P. C., Twelve Prophets, p. 38.
} 
Todos esses grupos são responsáveis por que o direito de Deus vigore

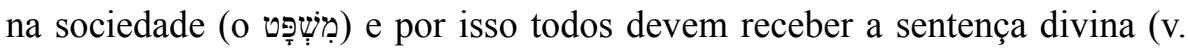
1d). Dessa forma, a frase "para vós é a sentença", que poderia ser traduzida

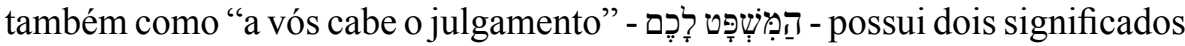
complementares: ser julgado e ser responsável pelo direito. ${ }^{7}$

\subsection{O discurso de YHWH (vv. 2-3)}

a) o evento de Sitim e a ação do Senhor (v. 2)

A perversão de Sitim eles aprofundaram, mas eu sou uma punição para todos eles.

$\mathrm{O}$ v. 2 apresenta grandes dificuldades textuais que, podendo acarretar diferenças significativas de significado para o texto em seu conjunto, exigem serem primeiramente abordadas.

- O termo da raiz שח, usada em dois sentidos: matar, assassinar e, daí, imolar, sacrificar; ou bater, malhar, daí maquinar, forjar. ${ }^{8}$ Embora podendo simplesmente significar matar pessoas (Jz 12,6; 1Rs 18,40; 2Rs 10,7; $\mathrm{Jr} 41,7)$ ou animais (Gn 37,31), a maior parte das ocorrências do verbo diz respeito à imolação ritual de animais $(\mathrm{Lv} 17,3 ; \mathrm{Nm} \mathrm{11,22;1 \textrm {Sm }}$ 1,$25 ; 14,32$; Is 22,13), também em relação a cultos idolátricos, incluindo o sacrifício de crianças (Is 57,5 ; Ez 16,21; 23,29). ${ }^{9} \mathrm{O}$ nome, por conseguinte, assume o valor de "imolação". ${ }^{10}$

\footnotetext{
${ }^{7}$ BEN ZVI, E., Hosea, p. 133.

8 BAUMGARTNER, W.; HARTMANN, B.; KUTSCHER, Y. (Eds.)., Hebräisches und Aramäisches Lexikon zum Alten Testament, p. 1352-1353; ALONSO SCHÖKEL, L., Diccionario Bíblico Hebreo-Español, p. 530; ZORELL, F., Lexicon Hebraicum et Aramaicum Veteris Testamenti, p. 833. Alguns autores corrigem o texto para שِ no sentido de poço, cisterna, também o lugar onde a caça é presa (WÄCHTER, L., שַָn, šahat, col. 1245-1248), o que caberia bem no contexto por seguir as imagens de caça presentes no versículo anterior. Assim WOLFF, H. W., Hosea, p. 119; JEREMIAS, J., Der Prophet Hosea, p. 73; SWEENEY, M. A., Hosea, p. 54. Neef sumariza as diferentes posições dos autores (NEEF, H.-D., Die Heilstraditionen Israels in der Verkündigung des Propheten Hosea, p. 211).

${ }^{9}$ CLEMENTS, R. E., שח šht, col. 1215-1217. Também ANDERSEN, F. I.; FREEDMAN, D. N., Hosea, p. 386.

${ }^{10}$ Assim ZORELL, F., Lexicon Hebraicum, p. 833, acepção seguida por MCCOMISKEY, T. E., Hosea, p. 75.
} 
Uma raiz semelhante, שחת, é usada em Os 9,9 no sentido de perverter-se, corromper-se, e em Os 11,9; 13,9 no sentido de destruir. ${ }^{11}$ A relação com 9,9 seria particularmente forte por este apresentar, como 5,2, também o verbo עמק hifil ("aprofundar"). A semelhança entre as duas raízes, que diferem somente na terceira consoante, próximas foneticamente, levanta a pergunta se o uso com $\Omega$ não seria uma peculiaridade do hebraico do Reino do Norte. ${ }^{12}$ Embora não haja dados para confirmar essa hipótese e, portanto, afirmar que o texto se refere à perversão, a ambiguidade do termo pode orientar para o fato que os dois sentidos estão sendo visados: a perversão consistiu num ato cultual ilícito, uma imolação sacrifical ocorrida em Sitim. Isto é corroborado pela relação que, nas tradições bíblicas, o nome Sitim tem com o culto cananeu (Nm 25,1). Em 5,2 e 9,9 seriam utilizadas duas raízes próximas criando um jogo de palavras, de modo que o pecado indicado em 5,2 teria sua consequência em $9,9 .{ }^{13}$

- O termo שָטִטים é igualmente pouco claro. É possível compreendê-lo como derivado da raiz שוט, "extraviar-se, perverter-se", ${ }^{14}$ daí a ideia de revolta e mentira. O termo indicaria, então os revoltosos, rebeldes ou corruptos. A raiz foneticamente próxima, טó, é usada no S1 101,3 com sentido de "desencaminhado, pervertido". ${ }^{15}$ Outra possibilidade é ver

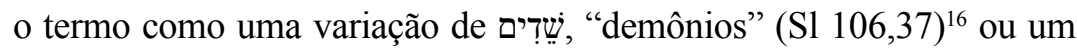
nome derivado da raiz שטם, "guardar rancor, odiar, hostilizar", designando alguém hostil (“a perversão/imolação daqueles que hostilizam”). Para outros, a palavra deriva da raiz שטה, usada para falar da infidelidade matrimonial (Nm 5,12.19-20.29). ${ }^{17}$ Por fim, com mudança de vocalização, lê-se o topônimo שִִ̣ים, Sitim, citado em Nm 25,1. Esta última proposta é particularmente adequada ao contexto, pois haveria, após a menção de dois locais, um terceiro, ${ }^{18}$ assim como ocorrem enumerações

\footnotetext{
${ }^{11}$ CONRAD, J., שחתht, col. 1234-1235. MACINTOSH lê em Os 5,2 e 9,9 a mesma raiz com $\Omega$ (MACINTOSH, A. A., A Critical and Exegetical Commentary on Hosea, p. 179). Igualmente, ALONSO SCHÖKEL vê o termo como derivado desta raiz (Diccionario, p. 756).

${ }^{12}$ SWEENEY, M. A., Hosea, p. 54.

${ }^{13}$ MORRIS, G., Prophecy, Poetry and Hosea, p. 86. No jogo de palavras há, a um tempo, dois aspectos: a semelhança de sons e a diferença de significado, sendo que é sobre este último que recai a atenção (MORRIS, G. Prophecy, p. 74).

14 ALONSO SCHÖKEL, L., Diccionario, p. 725.

15 ALONSO SCHÖKEL, L., Diccionario, p. 530.

${ }^{16}$ ALONSO SCHÖKEL, L., Diccionario, p. 749.

17 JACOB, E. Osée, p. 45.

18 MAZOR, Y., Hosea 5.1-3, p. 120.
} 
de três locais em outros textos do livro $(5,8 ; 6,7-9)$. A referência a Sitim enquadra-se igualmente bem no contexto do livro, que, na retrospectiva histórica que se inicia em 9,10, supõe o delito narrado em $\mathrm{Nm} 25$.

Também aqui poderia haver um jogo de palavras entre Sitim e os que se revoltam, desencaminham ou hostilizam, conforme a acepção que se dê ao termo. $^{19}$

A partir destas considerações, a primeira linha do v. 2 remete a um fato das tradições históricas israelitas ocorrido em Sitim e que inclui delitos no campo cultual.

A palavra do Senhor frente a isso é expressa, na linha seguinte, numa elipse: "Eu sou uma punição para todos eles", ou seja, um agente capaz de puni-los. A elipse traz para a frase uma maior força retórica. ${ }^{20}$

O vocábulo "punição" (מוֹסָ) é ligado ao âmbito sapiencial e legal (Pr $1,2.7 .8 ; 13,1 ; 23,23 ;$ Lv 26,18; Dt 22,18), particularmente no que se refere à educação familiar (Dt 21,18; $\operatorname{Pr} 4,1 ; 19,18$ ), em relação aos pais que educam o filho (Dt 8,5; $\operatorname{Pr} 31,1)$. Pode indicar o conteúdo que deve ser aprendido ( $\operatorname{Pr}$ $8,10 ; 21,1 ; 19,27 ; 24,32)$ ou o modo de ensinar, que implica disciplina ( $\mathrm{Pr}$ $13,24 ; 22,15 ; 23,13) .{ }^{21} \mathrm{O}$ termo encontra-se, assim, bem inserido no contexto de Oseias, que apresenta o Senhor na imagem do "pai", Israel sendo o "filho" (Os 11,1). Deus educa através da punição. ${ }^{22}$

O termo, no entanto, é encontrado na profecia, algumas vezes, indicando a punição divina, mas com referência ao fato que o povo não se submeteu ao agir do Senhor e, assim, não teve acesso à salvação (Is 26,16; Jr 2,3; 5,3; 7,28; 30,12-17; Sf 3,2.7), o que parece ser o caso aqui. Em si voltada para restaurar a ordem, ${ }^{23}$ a punição divina em Os 5,2 carrega o tom de uma última palavra, supondo, portanto, que a finalidade pedagógica divina não obteve êxito. Isso é corroborado pelo desenvolvimento do texto e sobretudo por sua sentença final (v. 7c).

\footnotetext{
${ }^{19}$ MORRIS, G., Prophecy, p. 121. O autor confirma essa interpretação com Os 4,15, onde, após dois nomes de locais (Guilgal e Bet-Áven) segue-se a frase "não jureis: Vive o Senhor", onde a raiz jurar (שבע) faz um jogo com o nome Beersheba (da mesma raiz), citado em Am 5,5, com o qual Os 4,15 tem profundas relações (JEREMIAS, J., Der Prophet Hosea, p. 71).

${ }^{20}$ BEN ZVI, E., Hosea, p. 130.

${ }^{21}$ BRANSON, R. D., יסר jasar. מוּרָ mûsar, col. 693-695.

${ }^{22}$ A raiz ocorre ainda em Os 7,12.15; 10,10; a ideia de educador, em Os 2,8-9.16-17; 3,4-5.

${ }^{23}$ LANDY, F., Hosea, p. 68.
} 
b) A ação do Senhor e o agir de Efraim-Israel (v. 3)

Eu conheci Efraim

e Israel não me estava oculto.

Pois bem: tu te prostituiste, Efraim,

contaminou-se Israel.

O discurso do Senhor continua, no v. 3, com a afirmação de sua comunhão com Israel, expressa pelo verbo "conhecer" (ידע). A menção de que Israel não lhe estava oculto sublinha a ideia do conhecimento: Deus conhece Israel total e profundamente (S1 69,6; 139,15), de modo que ele não se pode esconder de Deus. ${ }^{24}$ Deixa-se entrever, também aqui, um tom de ameaça. ${ }^{25}$

Alguns textos do livro que se referem aos primórdios da história israelita mostram o povo nos seus inícios a um tempo em seus aspectos favoráveis e desfavoráveis (Os 9,10;10,1). Considerada essa perspectiva, o tom apodítico da afirmação do v. 3 torna verossímil que também aqui a referência seja aos primeiros momentos da relação de Deus com Israel. Ou seja, a pecaminosidade de Israel se demonstra já nos primeiros momentos em que entra em contato com os povos cananeus $(9,10 ; 11,1-2 ; 13,5-6){ }^{26}$

Esse início, marcado pelo amor de Deus por Israel, portanto, conta também com o afastamento de Israel de seu Deus, aqui expresso com a metáfora da "prostituição". Recorrente no livro, ${ }^{27}$ esta imagem indica a infidelidade a Deus na busca da religião cananeia, o ir atrás dos "amantes", o deus Baal (2,7.18-19). Que a conduta passada, no entanto, continue no

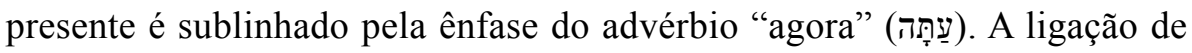
Israel com Baal torna-o impuro. "Contaminar-se" (טמא), de fato, concerne a aspectos cultuais, ${ }^{28}$ dentre os quais está a idolatria (Jr 2,7; Ez 36,17), que impede o acesso a Deus. ${ }^{29}$ Em sentido translato, indica ser impuro ou agir

\footnotetext{
${ }^{24}$ EISING, H., כחו khd, col. 140.

${ }^{25}$ RUDOLPH, W., Hosea, p. 121.

${ }^{26}$ LIMA, M. L. C., Os 9,10-17 nella dinamica del messaggio del libro di Osea, p. 159-162.

${ }^{27}$ Nele, a raiz ocorre diversas vezes: Os 1,$2 ; 2,6.7 ; 3,3 ; 4,10.12 .13 .14 .15 .18 ; 5,3.4 ; 9,1$.

${ }^{28}$ Lv 11,44; 13,3; 18,24; 20,25; 25,31; Nm 5,3; Dt 21,23; Ez 9,7; 18,6.

${ }^{29}$ A impureza é inconciliável com a santidade de Deus e assim são considerados impuros animais sagrados em outras religiões ou usados em cultos estrangeiros, atos cultuais estranhos ao javismo, elementos que têm relação com a geração da vida ou que estão ligados a situações de morte. ANDRÉ, G., טָָָׁ țame', col. 353.
} 
de modo impuro, em geral pelo exercício de culto estrangeiro (Ez 14,11; $20,7.18 ; 22,3-4){ }^{30}$

A distinção entre Efraim e Israel deve ser considerada em relação ao livro em seu conjunto. Em Oseias, o nome Israel pode designar o Reino do Norte, diferenciando-o de Judá $(7,1 ; 8,2.3 .5 ; 10,6 ; 13,9)$. Quando usado, porém, em relação aos primórdios da história, indica o povo descendente de Jacó, a totalidade das tribos $(9,10 ; 11,1 ; 12,13-14)$. Efraim pode designar o Reino do Norte $(5,11-14 ; 9,11.13 .16)$, o povo no seu conjunto $(5,9 ; 8,9.11$; $9,3)^{31}$ ou ainda a região montanhosa central ou a tribo que ali se estabeleceu $(4,17)$. Nesse último caso, refere-se à tribo dominante no Norte e, com isso, às classes dirigentes $(13,1)$, sentido preferível em 5,3 devido aos destinatários mencionados no v. 1. O par de palavras Efraim-Israel tem uma função retórica: evoca o todo e põe em relevo Efraim. ${ }^{32}$

\subsection{O comentário do profeta (vv. 4-7)}

a) A situação de Israel (v. 4)

Suas obras não (lhes) permitem que se voltem para o seu Deus, pois um espírito de prostituição está em seu meio e não conhecem o Senhor.

As primeiras considerações do profeta referem-se com precisão às palavras de Deus no v. 3. O v. 4, de fato, retoma em ordem inversa a ideia de prostituição e de conhecimento. Como no versículo anterior, a menção da prostituição no v. 4 tem um tom asseverativo ("Sim: um espírito de prostituição está em seu meio"), que lhe confere ênfase. A expressão "espírito de prostituição" designa uma força interior ${ }^{33}$ que domina, como que um segundo poder a condicionar o agir. ${ }^{34}$ Já mencionado em 4,12, tem aqui maior gravidade por se encontrar "em seu meio". ${ }^{35}$ Não se trata do interior, da capacidade de refletir e decidir de cada

\footnotetext{
${ }^{30}$ ANDRÉ, G., טֵָָׁ țe', col. 361.

${ }^{31}$ WOLFF, H. W., Hosea, p. 115. 212. 292.

${ }^{32}$ BEN ZVI, E., Hosea, p. 130.

${ }^{33}$ ALBERTZ, R.; WESTERMANN, C., ㄲำ rûah Espíritu, col. 929-930.

${ }^{34}$ RUDOLPH, W., Hosea, p. 121: impulso para a apostasia. Andersen e Freedman (Hosea, p. 391) veem aqui a indicação de um deus da religião cananeia, em contraposição ao Senhor que habita no meio de Israel $(11,9)$.

${ }^{35}$ JEREMIAS, J., Der Prophet Hosea, p. 76.
} 
israelita, para cuja realidade é usado em Oseias o termo לִ 2,$16 ; 4,11 ; 7,2.11$;

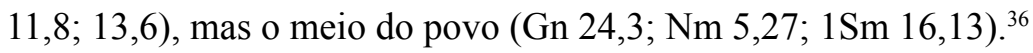

Por outro lado, se é possível considerar o "espírito de prostituição" como qualificação de Israel e Efraim (v. 3), a consideração de que o texto se refere sobretudo às classes dirigentes (v. 1) faz pensar que o "espírito de prostituição" seja especialmente relacionado com elas $^{37}$ e, nesse caso, de modo particular com os sacerdotes, responsáveis diretos pelo culto. De fato, em 4,12, o "espírito de prostituição" no povo é fomentado pelos sacerdotes, que negligenciam o ensinamento $(4,6)$ e realizam os sacrifícios em proveito próprio $(4,8)$; por isso serão especialmente punidos $(4,6.9)$.

A consequência aparece a seguir: eles "não conhecem o Senhor". Como “conhecer", em Oseias, indica o justo relacionamento com Deus $(4,1.6 ; 6,6)$, o "não conhecimento" expressa a separação, o afastamento que Israel tomou de seu Deus, ao ir atrás de Baal $(2,7.9 .14-15 ; 3,1)$. Ensinar o "conhecimento" é dever primordial do sacerdote, de modo que se enfatiza aqui, sob outro título, que eles são os responsáveis últimos pela sua falta $(4,6)$.

É este o motivo pelo qual não é possível voltar "para o seu Deus" (v. 4a), ${ }^{38}$ frase que, por estar isolada dentro das correspondências terminológicas existentes nos vv. 3-4, ganha valor por sua posição central. O "espírito de prostituição" cria uma realidade que faz de "suas obras" ações desviadas, ${ }^{39}$ incapazes de cumprir a vontade divina (o "conhecimento"). Não é explicado a que "obras" o profeta se refere; considerando, porém, o contexto imediato, poderiam ser os sacrifícios mencionados no v. 6, desligados de uma real conversão..$^{40} \mathrm{~A}$ meta do agir de Deus, de reconduzir Israel à comunhão consigo $(2,9 ; 3,5)$, torna-se impossível, pois o povo resiste a retornar a Deus $(7,10.16$; 11,5). ${ }^{41}$ O povo de Deus ("meu povo": 4,12) não mais alcança o "seu Deus", pois não se abre à conversão. Não é mais Deus que fará recair sobre Israel seus atos $(4,9)$, mas o próprio agir de Israel prepara-lhe a ruína ${ }^{42}$ (v. 5.7).

\footnotetext{
${ }^{36}$ WOLFF, H. W., Hosea, p. 104. Diferentemente: MACINTOSH, A. A. (Hosea, p. 184).

${ }^{37}$ WOLFF, H. W., Hosea, p. 126; ANDERSEN, F. I.; FREEDMAN, D. N., Hosea, p. 390.

${ }^{38} \mathrm{O}$ verbo נתן seguido de infinitivo tem sentido de "permitir": ALONSO SCHÖKEL, L. Diccionario, p. 520.

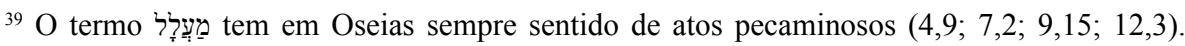
WOLFF, H. W., Hosea, p. 126.

${ }^{40} \mathrm{O}$ verbo שוב como verbo técnico para a conversão, no v. 4a.

${ }^{41}$ JEREMIAS, J., Der Prophet Hosea, p. 76.

${ }^{42}$ LANDY, F., Hosea, p. 69.
} 
b) O orgulho e seu resultado (v. 5)

Mas o orgulho de Israel testemunhará contra ele e Israel e Efraim tropeçarão em sua culpa.

Tropeçará também Judá com eles.

O v. 5 se inicia com linguagem jurídica, o testemunho dado num tribunal, ${ }^{43}$ que, no desenvolvimento do texto, aparece como resposta às palavras de Deus anteriormente pronunciadas (vv. 2-3) ${ }^{44} \mathrm{O}$ testemunho é dado pelo "orgulho de

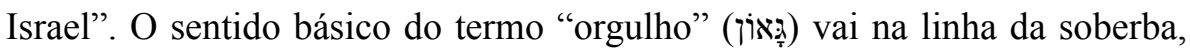
arrogância, altivez ${ }^{45}$ em perspectiva prevalentemente moral. ${ }^{46}$ No entanto, considerando que a temática central do contexto é de cunho teológico, o termo indica aqui, mais do que uma preocupação ética, a segurança em algo com o qual alguém se identifica (S1 47,5; Is 2,$10 ; 4,2 ; 24,14 ; 60,15)^{47} \mathrm{O}$ motivo poderia ser a situação de bem-estar e prosperidade, ${ }^{48} \mathrm{o}$ que levaria a supor a época de Jeroboão II. ${ }^{49}$ Todavia, no texto prevalece a orientação cultual ${ }^{50} \mathrm{e}$, mesmo sem se mencionar Baal, está pressuposto o culto cananeu. Isto implica que a "culpa" esteja ligada a este âmbito.

À luz dos capítulos precedentes, o problema cultual tem múltiplas facetas. De um lado, trata-se de atribuir a Baal e não ao Senhor os bens da terra $(2,7.10)$ e mesmo de cultuar Baal $(2,10.15)$ e as deusas de fertilidade $(4,12$ 13). De outro lado, trata-se também de cultuar o Senhor mas atribuindo-lhe as características de Baal (2,18: "tu não me chamarás mais 'meu Baal”"). Como maiores responsáveis por esta situação aparecem os sacerdotes, que se servem do culto javista para proveito próprio. Isso é corroborado pelo fato de que o termo "culpa" (עָ ) ser atribuído propriamente a esse grupo em 4,8. É todo o conjunto desses fatores que constitui o obstáculo que faz Israel e Efraim cair. A metáfora do "tropeçar", de fato, está ligada à ideia de ruína e pode indicar o cair (Is 3,8; Jr 6,15) ou o momento de vacilação anterior à queda (Is 8,15 ;

${ }^{43}$ É o sentido do sintagma ענה (בדֶ (LABUSCHAGNE, C. J., ענה I Responder, col. 433).

${ }^{44}$ SWEENEY, M. A., Hosea, p. 57.

${ }^{45}$ KELLERMANN, D., הָָลָ, col. 882-884.

${ }^{46}$ WOLFF, H. W., Hosea, p. 127; ANDERSEN, F. I.; FREEDMAN, D. N., Hosea, p. 392; LANDY, F., Hosea, p. 70; MACINTOSH, A. A., Hosea, p. 127.

${ }^{47}$ SIMIAN-YOFRE, H., El desierto de los dioses. Teología e Historia em el libro de Oseas, p. 81.

48 JEREMIAS, J., Der Prophet Hosea, p. 76.

${ }^{49}$ Assim RUDOLPH, W., Hosea, p. 121; MACINTOSH, A. A., Hosea, p. 186.

${ }^{50}$ A "prostituição" mencionada no v. 4 e suposta no v. 6. 
$\mathrm{Jr}$ 46,6.12.16). ${ }^{51} \mathrm{O}$ paralelismo entre Israel e Efraim aponta para a queda da nação como um todo e, em particular, de sua classe dirigente. A menção de Judá revela a releitura do texto no Reino do Sul..$^{52}$

c) Buscar e não encontrar (v. 6)

Com seu rebanho e seu gado caminharão

para buscar o Senhor,

mas não o encontrarão:

Ele se afastou deles.

O texto continua com a menção da ida ao santuário, que se torna inútil porque Deus já não está mais com o povo ("afastou-se deles"). A referência aos animais supõe que Israel busca encontrar a Deus com atos sacrificais ( $1 \mathrm{Sm}$ 15,14.21; Os 2,9). Todavia, como os sacrifícios cultuais mesmo javistas são parte da culpa de Israel, por ocorrerem sem o "conhecimento", não atingem a meta da comunhão com Deus. É possível que o texto aluda à ideia do mito de Baal: Baal está ausente (morto) na estação seca e retorna (revive) na época da chuva. ${ }^{53}$ Procurar com esta mentalidade não corresponde à vontade de Deus e ao sentido do culto em Israel: é já infidelidade $(4,8)$. Pois, pela falta de conhecimento (v. 4), a "busca" não é acompanhada da conversão $(3,5 ; 5,15 ; 7,10)$.

d) $\mathrm{O}$ veredito final (v. 7)

Ao Senhor traíram, pois filhos ilegítimos geraram.

Agora, a lua nova os devorará com sua herança.

O último versículo da perícope retoma a acusação e explicita a punição anunciada (v. 2). O tema é expresso pelo verbo בגד, que indica o agir traiçoeiro $(6,7)$, o agir em contradição com a justiça e a lealdade à comunidade, também a traição da mulher ao marido $\left(\operatorname{Ex~21,8;~Jr~3,20),~}{ }^{54}\right.$ conotação que retomaria aqui a imagem matrimonial tematizada explicitamente nos capítulos 1 a 3 .

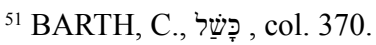

${ }^{52}$ SIMIAN-YOFRE, H., El desierto, p. 258.

${ }^{53}$ WOLFF, H. W., Hosea, p. 127; JEREMIAS, J., Der Prophet Hosea, p. 77.

${ }^{54}$ KLOPFENSTEIN, M. A., בגד bgd Ser desleal, col. 391.
} 
Com efeito, a traição se manifesta na geração de "filhos ilegítimos". O termo זุ não indica somente o estrangeiro $(7,9 ; 8,7$; Is 61,5$)$, o não israelita, ${ }^{55}$ mas o que não pertence à família (Dt 14,1) ou que se coloca contra a união, no caso, entre Israel e Deus $(8,12$; Is 1,$4 ; \mathrm{Jl} 4,17)$. Os "filhos ilegítimos" correspondem, assim, aos "filhos da prostituição" mencionados no início do livro $(1,2)$, o povo que se liga ao culto cananeu. Pode haver uma referência aos cultos que incluíam prostituição $(4,11-13)$ ou ao culto javista praticado com mentalidade cananeia, de modo que Israel, em vez de "filhos do Deus vivo" $(2,1)$, torna-se "filhos de Baal". ${ }^{56}$

O "agora" (עָתָת introduz, então, a palavra final. Chama a atenção a "lua nova" como agente do verbo "devorar" ${ }^{57}$ Embora seja possível ver nesse termo o nome de um deus, ${ }^{58}$ em 2,13 a "lua nova" está ligada a um culto que cessará. Dentro da mentalidade cananeia, ligada à fertilidade dos campos, o texto indicaria, então, que o culto, em vez de favorecer a produtividade, terá efeito contrário. A produção será aniquilada em virtude da falta do "conhecimento de Deus" que se manifesta num culto corrompido. Com efeito, nై é primeiramente uma porção de terra, a herança patrimonial $\left(\mathrm{Am} \mathrm{7,4)},{ }^{59}\right.$ o terreno que pertence a alguém. Como, no entanto, o termo é igualmente usado para a porção que cabia aos sacerdotes nos sacrifícios, ${ }^{60}$ o texto poderia indicar também que sacerdotes e seus filhos não mais a receberão $(4,6.8 .10)$. Pois os sacerdotes, os primeiros citados na abertura do texto (v. 1), apresentam-se como grupo especialmente visado, sobretudo se considerada a perspectiva propriamente cultual da acusação.

\footnotetext{
${ }^{55}$ MARTIN-ACHARD, R., זָ zar Extranjero, col. 728-730.

${ }^{56}$ JEREMIAS, J., Der Prophet Hosea, p. 77.

${ }^{57}$ A sintaxe deste último segmento não é clara. O termo "lua nova" pode ser visto como sujeito do verbo "devorar" ou como advérbio (na lua nova ele os devorará) (ANDERSEN, F. I.; FREEDMAN, D. N., Hosea, p. 596). Também o termo pode indicar o início do mês, o mês enquanto tal, um tempo determinado, favorável ou não (MACINTOSH, A. A., Hosea, p.189-190). ${ }^{58}$ Assim, Sweeney (Hosea, p. 58), apoiando-se em Dt 32, 17 e Jz 5,8, segue o parecer de Kuhnigh. Segundo este último, seria um título para Baal, pois ele seria o "novo", diverso do Senhor, que é Deus de Israel desde o Egito $(12,10 ; 13,4)$. E como nos mitos de Ugarit Baal tomaria o lugar do deus principal (KUHNIGH, W., Nordwestsemitische Studien zum Hoseabuch, p. 69-70).

${ }^{59}$ SCHMID, H. H., חלֶ hlq Dividir, col. 802.

${ }^{60}$ SWEENEY, M. A., Hosea, p. 59.
} 


\subsection{Os locais mencionados (v. 1ef-2a)}

Pois fostes um laço em Mizpa

e uma rede estendida no Tabor.

A perversão de Sitim eles aprofundaram.

Os três lugares mencionados são importantes, nas tradições israelitas, com respeito à nação como um todo: monarquia, sacerdócio e povo.

a) Mizpah

O nome deriva da raiz צפה, com sentido de guardar, vigiar e poderia indicar uma torre ou lugar elevado. No entanto, o paralelismo com Tabor fala em favor de uma referência geográfica. Embora o Antigo Testamento conheça diferentes localidades com esse nome, a referência mais provável é a Mizpah de Benjamin, a mais importante como local político, militar e religioso.$^{61} \mathrm{O}$ lugar aparece na lista de cidades benjaminitas conquistadas por Josué ( Jz 18,25-28). Em Mizpah, os israelitas se reúnem na guerra contra Benjamin (Jz 20,1.3) e, ao final, prometem não mais casar suas filhas com os homens de Benjamin (Jz 21,1). Segundo 1Sm 7,16, foi uma das cidades em que Samuel foi juiz, tendo ali reunido o povo para um evento cúltico em vista da ameaça dos filisteus (1Sm 7,5-7) e ali também escolhido, por sorte, Saul como chefe (1Sm 10,17-21).

O texto de 1Rs 15,16-22 indica que o rei Asa de Judá retirou pedras de Ramá (a $7 \mathrm{~km}$ ao norte de Jerusalém), que fora invadida e estava sendo fortificada por Baasa, rei de Israel, e com elas fortificou Gaba de Benjamin e Mizpah. Essa notícia coloca as duas fortalezas como elementos importantes na defesa da fronteira. Situadas em lugar de grande trânsito, segundo Arnold estas cidades provavelmente possuíam santuários para os deuses dos viajantes. ${ }^{62}$

A menção de Mizpa, portanto, evoca uma série de acontecimentos ligados à tribo de proveniência de Saul e à sua designação como chefe de Israel e, possivelmente, ainda a cultos estrangeiros.

\footnotetext{
${ }^{61}$ Seguimos aqui as indicações de ARNOLD, P. M., Mizpah (place), p. 879-881.

${ }^{62}$ A importância de Mizpah pode ser atestada ainda pelo fato que ali Godolias estabeleceu a capital após a queda de Jerusalém na mão dos babilônios (2Rs 25,23). Atualmente, sua localização é identificada com Tell En-Nasbeh, a 12 km de Jerusalém (FINKELSTEIN, I., O Reino esquecido, p. 58).
} 
b) Tabor

Trata-se de uma colina no Norte, ${ }^{63}$ que domina o vale de Jezrael e as principais vias da região. $\mathrm{Na}$ antiguidade seria provavelmente coberta por florestas. É possível que tenha sido um local de culto, pois Dt 33,18-19, mesmo sem citar o nome, refere-se a um monte na região de Zabulon e Issacar, em cujas fronteiras estava situado o Tabor. Também o texto de Jz 4,6.12.14, mencionando-o como lugar de reunião das tribos na batalha de Débora, indica ter sido uma cidade cultual da região. Pode-se pensar que em tempos pósexílicos fosse um local onde se acendia fogo para anunciar a lua nova. ${ }^{64} \mathrm{Se}$ isso se confirmasse também para tempos pré-exílicos, tornaria mais clara a menção da "lua nova" no v. 7 como um momento especial de culto - evidenciando, com isso, como o culto mal conduzido na época de Oseias acabaria por levar à ruína.

\section{c) Sitim}

É o último lugar onde Israel acampou antes de entrar na terra, onde o povo se preparou para atravessar o Jordão (Abel-Sitim: Nm 33,49), e marca o primeiro contato de Israel com os povos que habitavam a região. Este primeiro encontro é caracterizado negativamente pelo pecado dos israelitas que se uniram às mulheres moabitas e cultuaram Baal-Peor (Nm 25,1-5). Segundo o relato de Nm 25, ali o povo começou a prostituir-se (v. 1: זנה) e participou do culto aos deuses estrangeiros (v. 2), tendo por isso merecido a punição divina (v. 3-5).

${ }^{63} \mathrm{O}$ que é confirmado pelo uso da preposição עַ - e provavelmente não a área em torno de Betel, citada em 1Sm 10,3 (FRANKEL, R., Tabor, Mount, p. 304; WEI, T. F., Tabor, Oak of (place), p. 305). Se indicasse esta localidade, também aqui poderia haver uma nova referência, embora indireta, à eleição de Saul.

${ }^{64}$ Assim FRANKEL, R., Tabor, Mount, p. 305, citando o Talmud de Rosh Hashanah:

"Originally they used to light beacons. When the cutheans [samaritans] adopted evil courses, they made a rule that messengers should go forth. How did they light the beacons? They used to bring long poles of cedar and reeds and olive wood and flax fluff which they tied to the poles with a string, and someone used to go up to the top of a mountain and set fire to them and wave them to and fro and up and down until he saw the next one doing the same thing on the top of the second mountain; and so on the top of the third mountain. Whence did they carry the [chain of] beacons? From the mount of olives [in Jerusalem] to Sartaba, and from Sartaba to Grofina, and from Grofina to Hauran, and from Hauran to Beth Baltin the one on Beth Baltin did not budge from there but went on waving to and fro and up and down until he saw the whole of the diaspora before him like one bonfire". (Disponível em: $<$ https://juchre.org/talmud/rosh/rosh2. htm\#chap02>. Acesso em: 3 mai. 2018). 


\section{A meta do texto}

Duas imagens do mundo da caça servem para expressar o agir das classes dirigentes. Primeiramente, a armadilha para pássaros (חפ), muito usada para falar de uma cilada (S1 140,6; Jr 18,22) ou simplesmente de perigos $(\operatorname{Pr} 22,5)$. A segunda é a imagem da rede (רֶֶֶ), também usada para capturar pássaros (Pr $1,17)$. Como o pássaro preso no laço ou na rede morre, assim é o povo diante dos governantes, que agem iniquamente, preparando ciladas $(6,9)$.

O texto desenvolve primordialmente o tema do culto. Além da terminologia empregada, a referência ao Tabor e a Sitim ligam-no propriamente a tradições cultuais. Todavia, não é somente aos sacerdotes que se dirige: a acusação divina e as palavras do profeta dizem respeito aos três grupos mencionados no início do v. 1. Nesse sentido, a menção de Mizpah, embora também podendo referir-se a cultos estrangeiros, liga-se mais fortemente à eleição de Saul e, por conseguinte, à monarquia no Reino do Norte, que é especialmente visada por Oseias. Este fato juntamente com a menção de três dos grupos dirigentes implica a profunda relação que, segundo o profeta, existe entre corrupção do culto e corrupção da política. Em outras palavras, pela referência a locais ligados ao culto e à monarquia, entende-se que o profeta associe numa só acusação sacerdotes, de um lado, e casa de Israel e corte, de outro.

O livro, com efeito, critica duramente a monarquia tal como se dava no Israel de sua época $(1,1)$, os últimos anos do Reino do Norte, a partir de Jeroboão II e com as sucessões violentas dos reis, que subiam ao trono a partir de revoltas e assassinatos $(7,7 ; 8,4)$. Trata-se de uma monarquia fraca $(10,3.7$; $13,10.11)$, corrompida pela influência dos que detinham algum poder $(7,3 ; 8,4)$. Dentre esses, também a classe sacerdotal, que oficiava em Betel, e que será corresponsável pelo fim da monarquia $(10,15 ; 1,4) .{ }^{65} \mathrm{~A}$ crítica ao sacerdócio é particularmente áspera e pode ser sintetizada no fato que os sacerdotes se servem do culto para influenciar as classes políticas, ${ }^{66}$ negligenciando aquelas que seriam suas funções primordiais.

Tanto num como noutro caso, não se trata de uma visão negativa da instituição monárquica ou sacerdotal, mas da acusação, que não deixa de supor uma grande desilusão, de seus desvios. Particularmente em se tratando da classe sacerdotal, a crítica do profeta faz entrever o alto conceito que tinha

\footnotetext{
${ }^{65}$ Sobre a crítica à monarquia, SIMIAN-YOFRE, H., El desierto, p. 215-219.

${ }^{66}$ Sobre a crítica o sacerdócio e ao culto, SIMIAN-YOFRE, H., El desierto, p. 219-228.
} 
do sacerdócio e, nisso, a gravidade de seus delitos, por isso tanto mais dignos de repreensão, acusação e punição.

A recordação das tradições ligadas aos três locais mencionados é feita em duas perspectivas, que correspondem ao fato que os dois primeiros pertencem à fala do profeta e o último, à de Deus. De um lado, Mizpah e Tabor são colocados em relação a malfeitos atuais, difíceis de precisar devido ao caráter genérico do texto. De outro, a menção de Sitim serve a indicar que o presente é ainda mais pecaminoso do que o que ocorreu no passado. Se nos primeiros contatos com os povos cananeus Israel já assumiu elementos religiosos espúrios, agora se confirma como este atrai e domina o povo e influencia mesmo aquela classe responsável pela pureza da religião. Com isso, podese supor que o agir dos dirigentes em Mizpa e Tabor são delitos ainda mais graves do que o ocorrido em Sitim.

Em síntese, indigitando particularmente seus governantes e sacerdotes, o texto visa demonstrar a gravidade da culpa de Israel e como ela se intensificou com o passar do tempo, de modo que chegou a tornar Israel incapaz não só de se aproximar de Deus mas também de uma real conversão. Embora a dimensão política esteja presente, é sobretudo o aspecto religioso-cultual a preocupação do profeta: o "espírito de prostituição", a "contaminação" de Israel, a "falta de conhecimento" de seu Deus. Tudo isso considerado, a partir da analogia matrimonial, profunda traição e adultério que gera filhos ilegítimos. Nesse contexto, o culto não cumpre a finalidade para a qual foi instituído; Deus não se deixará encontrar. Tal estado levará inevitavelmente à ruína não só da religião mas também da nação enquanto tal, pois Deus não está mais com o povo. Expressa-se, assim, o mesmo pensamento que, na abertura do livro, dava ao terceiro filho do profeta o nome: "Não-meu-povo" $(1,9)$ : a quebra mais total da relação entre Israel e seu Deus e, com isso, o fim de Israel enquanto povo de Deus. Por trás de toda a acusação, demonstra-se como Deus tinha para com seu povo uma meta de comunhão.

\section{Conclusão}

Apesar das grandes dificuldades que o texto de Os 5,1-7 oferece, suas linhas centrais são suficientemente claras. $O$ profeta se dirige àqueles que, responsáveis pelo direito, não só negligenciam seu dever, mas tornam-se ainda ocasião de queda para o povo em seu conjunto.

A acusação divina (vv. 2-3) carrega ainda mais o peso desses delitos, 
que ultrapassa o dos desvios conhecidos em Nm 25. Embora incluindo os dirigentes políticos, é sobretudo a situação religiosa sua preocupação: a falta de conhecimento de Deus, o culto cananeu e mesmo sincrético.

As palavras do profeta (vv. 4-7) tiram as consequências da acusação divina e explicitam seus elementos, culminando na sentença de que o agir de Israel lhe acarretará a queda. Com isso, o texto demonstra como os aspectos cultuais não dizem respeito somente ao âmbito religioso, mas têm consequências para a história, seja no que tange à política interna, com a fraqueza e decadência da monarquia, seja no fato que esta mesma política colocará Israel como presa fácil dos poderes estrangeiros.

\section{Referências bibliográficas}

ALBERTZ, R.; WESTERMANN, C. ㄲำ rîn Espiritu. In: JENNI, E.; WESTERMANN, C. (Eds.). Diccionario teologico manual del Antiguo Testamento. Madrid: Cristiandad, 1985. vol. II. col. 914-947.

ALONSO SCHÖKEL, L. Diccionario Bíblico Hebreo-Español. Madrid: Trotta, 1994.

ANDERSEN, F. I.; FREEDMAN, D. N. Hosea. New York: Doubleday, 1980. ANDRÉ, G. טָׁמָא țame'. In: BOTTERWECK, G. J.; RINGGREN, H.; FABRY, H.-J. (Eds.). Theologisches Wörterbuch zum Alten Testament. Stuttgart Berlin - Köln - Mainz: W. Kohlhammer, 1986. vol. III. col. 352-366.

ARNOLD, P. M. Mizpah (place). In: FREEDMAN, D. N. (Ed.). The Anchor Bible Dictionary. New York: Doubleday, 1992. vol. IV. p. 879-881.

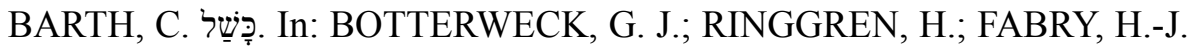
(Eds.). Theologisches Wörterbuch zum Alten Testament. Stuttgart - Berlin - Köln - Mainz: W. Kohlhammer, 1986. vol. IV. col. 367-375.

BAUMGARTNER, W.; HARTMANN, B.; KUTSCHER, Y. (Eds.). Hebräisches und Aramäisches Lexikon zum Alten Testament. Leiden: Brill, 1990. vol. I / II.

BEN ZVI, E. Hosea. Grand Rapids, MI / Cambridge, UK: William B. Eerdmans Publishing Company, 2005.

BRANSON, R. D. יסר מוּסָר. mâsar. In: BOTTERWECK, G. J.; RINGGREN, H.; FABRY, H.-J. (Eds.). Theologisches Wörterbuch zum 
Alten Testament. Stuttgart - Berlin - Köln - Mainz: W. Kohlhammer, 1986. vol. III. col. 688-697.

CLEMENTS, R.E. שחת šht. In: BOTTERWECK, G. J.; RINGGREN, H.; FABRY, H.-J. (Eds.). Theologisches Wörterbuch zum Alten Testament. Stuttgart - Berlin - Köln - Mainz: W. Kohlhammer, 1986. vol. VII. col. 12141218.

CONRAD, J. שִ šht. In: BOTTERWECK, G. J.; RINGGREN, H.; FABRY, H.-J. (Eds.). Theologisches Wörterbuch zum Alten Testament. Stuttgart Berlin - Köln - Mainz: W. Kohlhammer, 1986. vol. VII. col. 1233-1245.

CRAIGIE, P. C. Twelve Prophets: Hosea, Joel, Amos, Obadiah, and Jonah. Louisville-London: Westminster John Knox Press, 1984.

EISING, H. כוזר kh. In: BOTTERWECK, G. J.; RINGGREN, H.; FABRY, H.-J. (Eds.). Theologisches Wörterbuch zum Alten Testament. Stuttgart Berlin - Köln - Mainz: W. Kohlhammer, 1986. vol. IV. col. 137-141.

ELLIGER, K. Eine verkannte Kunstform bei Hosea (Zur Einheit von Hos 51f.). Zeitschrift für die alttestamentliche Wissenschaft v.69, n.1-4, p. 151160, 1957.

FINKELSTEIN, I. O Reino esquecido. Arqueologia e história de Israel Norte. São Paulo: Paulus, 2015.

FRANKEL, R. Tabor, Mount. In: FREEDMAN, D. N. (Ed.). The Anchor Bible Dictionary. New York: Doubleday, 1992. vol. VI. p. 304-305.

JACOB, E. Osée. In: JACOB, E.; KELLER, C.-A.; AMSLER, S. (Eds.). Osée, Joel, Abdias, Jonas, Amos. Neuchâtel: Labor et Fides, 1965.

JEREMIAS, J. Der Prophtet Hosea. Göttingen: Vandenhoeck \& Ruprecht, 1983.

KELLERMANN, D. הָָָּּ In: BOTTERWECK, G. J.; RINGGREN, H.; FABRY, H.-J. (Eds.). Theologisches Wörterbuch zum Alten Testament. Stuttgart - Berlin - Köln - Mainz: W. Kohlhammer, 1986. vol. I. col. 878-884. KLOPFENSTEIN, M.A. בגד bgd Serdesleal. In: JENNI, E.; WESTERMANN, C. (Eds.). Diccionario teologico manual del Antiguo Testamento. Madrid: Cristiandad, 1985. vol. I. col. 387-392.

KUHNIGH, W. Nordwestsemitische Studien zum Hoseabuch. Roma: Pontificio Istituto Biblico, 1974. 
LABUSCHAGNE, C. J. ענה I Responder. In: JENNI, E.; WESTERMANN, C. (Eds.). Diccionario teologico manual del Antiguo Testamento. Madrid: Cristiandad, 1985. vol. II. col. 427-435.

LANDY, F. Hosea. Sheffield: Sheffield Academic Press, 1995.

LIMA, M. L. C. Os 9,10-17 nella dinamica del messaggio del libro di Osea. In: OBARA, E. M.; SUCCU, G. P. D. (Eds.). Uomini e profeti. Roma: Gregorian \& Biblical Press, 2013. p. 157-193.

MACINTOSH, A. A. A Critical and Exegetical Commentary on Hosea. Edinburgh: T\&T Clark, 1997.

MARTIN-ACHARD, R. זָ zar Extranjero. In: JENNI, E.; WESTERMANN, C. (Eds.). Diccionario teologico manual del Antiguo Testamento. Madrid: Cristiandad, 1985. vol. I. col. 728-730.

MAZOR, Y. Hosea 5.1-3: Between Compositional Rhetoric and Rhetorical Composition. Journal for Study of the Old Testament. v.14, n.45, p. 115126, out. 1989.

MCCOMISKEY, T. E. Hosea. In: MCCOMISKEY, T. E. (Ed.). The Minor Prophets: An Exegetical and Expository Commentary. Grand Rapids (MI): Baker Academic, 2009.

MORRIS, G. Prophecy, Poetry and Hosea. Sheffield: Sheffield Academic Press, 1996.

NEEF, H.-D. Die Heilstraditionen Israels in der Verkündigung des Propheten Hosea. Berlin - New York: De Gruyter, 1987.

RINGGREN, H. עגֶֶר 'egael. In: BOTTERWECK, G. J.; RINGGREN, H.; FABRY, H.-J. (Eds.). Theologisches Wörterbuch zum Alten Testament. Stuttgart - Berlin - Köln - Mainz: W. Kohlhammer, 1986. vol. V. col. 10561061.

RUDOLPH, W. Hosea. Gütersloh: Gütersloher Verlagshaus Gerd Mohn, 1966.

SCHMID, H. H. חלֶ ḩlq Dividir. In: JENNI, E.; WESTERMANN, C. (Eds.). Diccionario teologico manual del Antiguo Testamento. Madrid: Cristiandad, 1985. vol. I. col. 800-804.

SIMIAN-YOFRE, H. El desierto de los dioses. Teología e Historia en el libro de Oseas. Cordoba: El Almendro, 1993. 
SWeEney, M. A. Hosea. In: SWEeney, M. A. The Twelve Prophets. Collegeville, MINN: Liturgical Press, 2000. vol. I.

TALMUD de Rosh Hashanah. Disponível em: <https://juchre.org/talmud/ rosh/rosh2.htm\#chap02>. Acesso em: 3 mai. 2018.

WÄCHTER, L. שֵ šahat. In: BOTTERWECK, G. J.; RINGGREN, H.; FABRY, H.-J. (Eds.). Theologisches Wörterbuch zum Alten Testament. Stuttgart - Berlin - Köln - Mainz: W. Kohlhammer, 1986. vol. VII. col. 12451248.

WEI, T. F. Tabor, Oak of (place). In: FREEDMAN, D. N. (Ed.). The Anchor Bible Dictionary. New York: Doubleday, 1992. vol. VI. p. 305.

WOLFF, H. W. Hosea. Neukirchen-Vluyn: Neukirchener Verlag, $1976^{3}$. (Dodekapropheton, 1).

ZORELL, F. Lexicon Hebraicum et Aramaicum Veteris Testamenti. Roma: Pontificio Istituto Biblico, 1968.

Maria de Lourdes Corrêa Lima

Doutora em Teologia Bíblia pela Pontificia Università Gregoriana (Roma) Docente de Sagrada Escritura na Pontifícia Universidade Católica do Rio de Janeiro Rio de Janeiro / RJ - Brasil E-mail:mllima@puc-rio.br

Recebido em: 07/06/18

Aprovado em: 28/07/18 